\title{
FUNDA TOPRAK, HOCA NAZAR HÜVEYDĀ, RĀHAT-I DİL (İNCELEME- METIN-DIZIN), GRAFIKER YAYINLARI, 524 s.
}

Yaşar TOKAY

\begin{abstract}
Özet
Çağatay Türkçesi, yaklaşık olarak beş yüz yıl boyunca Orta Asya Türklüğünün ortak yazı dili olma özelliğini kazanmış tarihî Türk yazı dillerinden biridir. Bu dönemin hemen her asrında önemli temsilciler ortaya çıkmıştır. Başlangıç döneminde Mevlana Sekkâkî, Ataî, Gedâî, Haydar Harezmî, Yusuf Emirî, Yakınî; Klasik dönemlerinde Ali Şîr Nevâyî, Hüseyin Baykara ve Babür Şah gibi sanatçılar barındırmıştır. Bu tanıtma yazısında, Son Dönem Çağatay sanatçılarından kabul edilen Hoca Nazar Hüveydā'nın Rāhat-1 Dil adlı mesnevisinin bilimsel yayını ele alınmaktadır. Eserin Çağatay Türkçesindeki yeri, ses ve biçim özellikleri ile söz varlığı hakkında bazı bilgiler verilmekte ve bu akademik çalışma ile ilgili dikkate değer hususlar belirtilmeye çalışılmıştır.
\end{abstract}

Anahtar Kelimeler: Çağatay Türkçesi, Hoca Nazar Hüveydā, Rāhat-1 Dil.

\section{FUNDA TOPRAK, HOCA NAZAR HÜVEYDĀ, RĀHAT-I DİL (İNCELEME- METIN-DİIIN), GRAFIKER YAYINLARI, $524 \mathrm{~s}$.}

\begin{abstract}
Chagatai Turkish, approximately five hundred years Central Asia gained the distinction of being common written language is one of the historical Turkish written language. During this period, a significiant representation has emerged in almost every century. Before the classical period, Mevlana Sekkâkî, Ataî, Gedâî, Haydar Harezmî, Yusuf Emirî, Yakınî and in the classical period, such writers as Ali Şîr Nevâyî, Hüseyin Baykara ve Babür Şah has hosted. In this introduction letter, accepted the writer of the last Chagatai Period, Hoca Nazar Hüveydā's masnavi Rāhat-1 Dil, discusses the scientific publication of his work. Author's position in the Chagatai Turkish, phonetic and morphological properties are given some information about the existence of issues related to this remarkable promise and academic studies have tried to be specified.
\end{abstract}

Key Words: Chagatai Turkish, Hoca Nazar Hüveydā, Rāhat-1 Dil.

"Funda TOPRAK, Hoca Nazar Hüveydā, Rāhat-1 Dil (İnceleme-Metin-Dizin), Grafiker Yayınları, 524 s."

Orta Asya'da beş yüz yıl kadar ortak yazı dili kabul edilen Çağatay Türkçesi, genel olarak XV. ve XX. asırlar arasındaki dönemi kapsar. Çağatay Türkçesi üzerine çalışan bilim insanlarından Samoyloviç, Mehmed Fuad Köprülü, Şçerbak ve Janos Eckmann gibi birçok Türkolog, Çağatay Türkçesini çeşitli dönemlere bölerek ele almışlardır. Ancak genel olarak bu dönemin Klasik Öncesi Devir, Klasik Devir ve Klasik Sonrası Devir olmak üzere tasnif edilmesi üzerinde görüş birliği bulunmaktadır.

Çağatay Türkçesinin Klasik Öncesi dönemlerinde Mevlana Sekkâkî, Ataî, Gedâî, Ahmedî, Seyyid Ahmed Mirza, Haydar Harezmî, Yusuf Emirî ve Yakınî gibi sanatçılar bu dönemin temellerini atarken, Çağatay edebiyatı; Ali Şîr Nevâyî, Hüseyin Baykara ve Babür Şah

\footnotetext{
${ }^{1}$ Arş. Gör., Ankara Yıldırım Beyazıt Üniversitesi, İnsan ve Toplum Bilimleri Fakültesi, Türk Dili ve Edebiyatı Bölümü, ANKARA, el-mek: erciyes_yasar@hotmail.com
} 
gibi sanatçılarla en parlak devrini yaşamıştır. Çağatay Türkçesinin son devri, özellikle Klasik dönemden sonra silik kalmasına rağmen yine de birçok temsilci yetiştirmiş̧ir. Bunlar arasında en çok bilinenleri olarak Hoca Nazar Hüveydâ, Mahdum Kulu, Ubeydî, Beyzâ, Gazâlî, Firkat gösterilebilir (Eraslan 1993: 175).

Elimizdeki çalışma Klasik Sonrası Devir sanatçısı olan Hoca Nazar Hüveydâ'nın Rāhat1 Dil adlı mesnevisinin bilimsel yayını içermektedir. Sanatçının Rāhat-1 Dil adlı mesnevisinden başka bir de Dîvân'ı bulunmaktadır.

Hoca Nazar Hüveydâ'nın eserleri ilk olarak M. Hartmann ve M.F. Gavrilov tarafından ele alınmıştır. Daha sonraları Hoca Nazar Hüveydâ'nın şiirleri çeşitli antolojilerde yer bulmuştur. Bu araştırmacıların yanında eser üzerinde çalışan V. Zahidov (1975) ve Tohtasın Celalov (1976)'dan da söz etmek gerekir. Özellikle, Özbekistan ve Afganistan'da çok tanınan Hoca Nazar Hüveydâ, ülkemizde ansiklopedilerde geçen kısa bilgileri bir kenara koyarsak pek tanınmamıştır. Türkiye'de bu konuda yalnızca Bedriye Kaya'nın " Hoca Nazar Hüveydâ ve Divanının Analizi: Metin Dil ve Edebî İçerik Yönünden İncelenmesi" (Kaya, 2012) başlıklı bir yüksek lisans tezi bulunmaktadır.

Hoca Nazar Hüveydâ, 1704 yılında bugün Kırgızistan'da bulunan Oş şehrinde dünyaya gelmiş̧tir. Babası Gayib Nazar, tasavvuf ehli bir insan olduğundan Hoca Nazar Hüveydâ da aynı hayat tarzını benimsemiştir. Hoca Nazar Hüveydâ'nın talebeleri tarafından verilen bilgilere göre sanatçı, 1780 yılında vefat etmiştir (Toprak, 2017: 16-17).

Tanıtmaya çalışacağımız yayın, Afganistan'da yapılan bir tıpkıbasım esas alınarak ortaya konmuştur. Çalışma, temelde beş ayrı bölüm şeklinde oluşturulmuştur:

Birinci bölümde (s. 13-35); Hoca Nazar Hüveydâ'nın kısa yaşam öyküsü ve eserleri ile Rāhat-1 Dil'in içeriği hakkında önemli bilgiler bulunmaktadır. Rāhat-1 Dil, Hüveydā'nın ahlakîdidaktik bir mesnevisidir ve yazarın Dîvân'ında bulunur. Araştırmacıya göre, bu mesnevi Dîvân'a sonradan eklenmiştir. Eserde açgözlülük, vefa, fanilik, iyiliğin faydaları, güzellik ve manevî temizlik gibi birçok konu üzerinde durulmuştur.

Araştırmacı, eserin sayfa kenarlarına iliştirilmiş bazı Kıyāmet-nāmelerden de bahsetmektedir. Hocamız, bu eserde altı Kıyāmet-nāme tespit etmiştir. Bu Kıyāmet-nāmeler üzerine ayrıca bir makale de yayımlamıştır (Toprak, 2012: 179).

$\mathrm{Bu}$ bölümde üzerinde durulan ve sanatçının eserini neden Türkçe yazdığını anlattığı mısralar dikkat çekicidir:

Köyülnì şehri sarı 'azm kıldım

Kitābım nesr èrdi nazm ḳıldım

Bu Çimyān şehriniy pîr ü cevānı

Tamāmısı èrürler Türkî ḩānı

Alar Tācik söziġa bî-hünerrak

Dédim bolsa kitābım Türkî bihrak

İnāyet boldı Tayridın be-yekbār

Sevād èttim nèçe manzūme ey yār 
Yukarıdaki mısralardan da anlaşıldığı üzere Hoca Nazar Hüveydā, Farsçayı çok da iyi bilmeyen Türkler için bu eseri nesirden nazıma çekerek, herkes rahatlıkla okusun diye özellikle Türkçe yazmıştır.

Rāhat-1 Dil'in özelliklerinden bahsedilirken eserin içeriği ile ilgili önemli tespitler yapıldığı görülür. Mesnevi türünde yazılan eser, kendi içinde muhtelif ve farklı konularda yazılan başka parçalar da ihtiva etmektedir. Örneğin, eserin Sebeb-i Nazm-ı Kitāb bölümünü takip eden sayfalarda Slfat-ı Duzah "Cehennemin Özellikleri" başlığı altında başka bir mesnevi daha yer almaktadır. Bu parçadan sonra Behişt Sıfatı "Cennetin Özellikleri" adlı farklı bir mesnevi daha yer almaktadır.

Araştırmacı tarafından tespit edilen en önemli parçalardan biri de eserin 53. ve 73 . Beyitleri arasında yer alan Nür-nāme örneğidir. Bununla birlikte eserde yer alan kıssalar ve hikâyeler, bu bölümde kısaca tanıtılmıştır.

Eserde, kimi zaman dinî literatüre ait parçalar da bulunmaktadır. Özellikle, Yalgançılık başlı̆̆ını taşıyan bölümde yer alan Ebu Hureyre hikâyesi, Hazret-i Rabia kıssası ve Habib-i Gamhar kıssası bunlardan bazılarıdır.

Çalışmanın bu bölümünde Rāhat-1 Dil'in söz varlığı ile ilgili önemli tespitler bulunmaktadır. Araştırmacıya göre, Hüveydā'nın dilinde yerel şiveye ait olduğu düşünülen çok sayıda ifade vardır. Bunlardan bazıları şöyle sıralanmıştır: 'ibādet yokssızı "İbadet yoksunu", bir

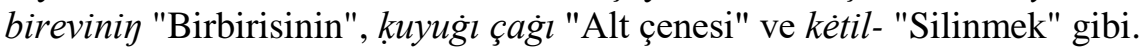

Eserde araştırmacı tarafından tespit edilen ilgi çekici sözcükler de vardır. Bu sözcüklere kün çıkarda "Doğu, maşrı", tayla "Kıyamet", devāmet "Sürekli, devamlı" gibi kullanımlar örnek gösterilebilir.

Araştırmacı, eserin söz varlığında deyimlerin önemli bir yer tuttuğundan bahseder ve dikkat çekici kimi deyimlerle ilgili örnekleri sıralar. Bu deyimlerden bazıları şunlardır: bād-ı ecel tég- "Ecel rüzgârı değmek; ölmek", muşibet tonı kèy- "Gamlı ve yaslı olmak", kögli sinuk "Kalbi kırık" gibi.

Çalışmanın ikinci ve üçüncü bölümünde eserin Dil İncelemesi (Ses ve Biçim Özellikleri) (s. 37-70) yer almaktadır. Eserin fonetik ve morfolojik özelliklerinin yer aldığı bu bölüm, eserin gramer yönünden içerdiği bilgileri kısaca aktarma amacı taşımaktadır. Çağatay Türkçesinin dikkat çekici özelliklerinden biri kabul edilen ve Janos Eckmann'ın şehirlerde kullanılan Özbekçenin tesiriyle açıkladığı (Eckmann, 1996: 113) kalınlık-incelik uyumuna aykırı kullanımlar, bu metinde de oldukça fazladır.

Eserin imla özellikleri noktasında verilen bilgiler, imladaki düzensizlik ve ikili yazımlarla ilgilidir. Klasik Çağatay Türkçesinin en önemli fonetik özelliklerinden olan zamir n'si, bu eserde de oldukça az kullanılmıştır. bölümdür.

Dördüncü bölüm (s.73-283), Rāhat-1 Dil'in transkripsiyonlu metninin yer aldığ

Beşinci bölümde (s. 287-488), eserin Gramatikal Dizin'i yer almaktadır. Özellikle, tarihî Türk yazı dilleri üzerine çalışma yapacak araştırmacılara kolaylık sağlamak amacıyla hazırlanan bu bölüm, oldukça kullanışlıdır. Sözcükler, metin içerisinde geçtikleri yerle birlikte kökenleri de ele alınarak sıralanmıştır.

Gramatikal Dizin'in en önemli özelliklerinden biri de, eserde geçen deyimlerin ayrı maddeler halinde alfabetik olarak siralanmasıdır. Örneğin; acıg் k kel- "Teessüfte bulunmak, hayıflanmak", bug tart- "Boru üflemek"; fikr sal- "Düşünmek" ve köylini avla- "Gönlünü kazanmak" gibi.

Gramatikal Dizin'i Kaynaklar (s. 489) ve Metin Örnekleri (s. 493-523) başlıkları izlemektedir. 
Son dönem Çağatay edebiyatı üzerine yapılan bu çalışma Hoca Nazar Hüveydā'nın ülkemizde tanınması noktasında dikkat çekici bir yayındır. Çağataycanın Özbekçeye geçiş süreci kapsamında değerlendirilebilecek bu eserin söz varlığg da önemli derecede orijinallik taşımaktadır. Çalışmada Gramatikal Dizin'in yer alması bundan sonra araştırma yapacak bilim insanlarına kolaylık sağlayacaktır. Son olarak, Sayın Funda Toprak hocamızı, bu titiz çalışması sebebiyle tebrik eder ve yeni çalışmalarını beklediğimizi ifade etmek isteriz.

\section{Kaynakça}

ECKMANN, J. (1996). Harezm, Kıpçak ve Çağatay Türkçesi Üzerine Araştırmalar, Ankara: TDK Yayınları.

ECKMANN, J. (2003). Çağatay Edebiyatının Son Devri, Haz: Osman Fikri Sertkaya, Harezm, Kıpçak ve Çağatay Türkçesi Üzerine Araştırmalar, s. 208-243, Ankara: TDK Yayınları.

ERASLAN, K. (1993). Çağatay Edebiyatı, İslam Ansiklopedisi, C. 8, s. 168-176.

KAYA, B. (2012). Hoca Nazar Hüveydā ve Divanının Analizi: Metin Dil ve Edebî İçerik Yönünden İncelenmesi, Yayımlanmamış Yüksek Lisans Tezi, İstanbul: Fatih Üniversitesi, Sosyal Bilimler Enstitüsü.

TOPRAK, F. (2012). Hoca Nazar Hüveydā'nın Kıyāmet-nāmeleri, Turkish Studies, Volume 7/14, s. 179-213.

TOPRAK, F. (2017). Hoca Nazar Hüveydā, Rāhat-ı Dil (Inceleme-Metin-Dizin), Ankara: Grafiker Yayınları. 